\title{
Strangulated Epigastric Hernia: A Rare Occurrence
}

Sri Hari Priya Vemulakonda ${ }^{1}$, Souradeep Dutta ${ }^{1}$, Ankit Jain ${ }^{1}$, Abhinaya Reddy ${ }^{1}$, Vishnu Prasad Nelamangala Ramakrishnaiah ${ }^{1}$

1. Surgery, Jawaharlal Institute of Postgraduate Medical Education and Research, Puducherry, IND

Corresponding author: Vishnu Prasad Nelamangala Ramakrishnaiah, vprasad285@gmail.com

\begin{abstract}
An epigastric hernia is a rare type of abdominal hernia, described in the literature mostly as small, containing only preperitoneal fat. A large true epigastric hernia with herniation of the abdominal viscera is even rarer. Only a few case reports have given an account of strangulation in such an epigastric hernia. This case report describes a middle-aged, morbidly obese man with a big epigastric hernia presenting with incarceration and acute abdominal pain. Emergency surgical exploration revealed a $7 \mathrm{~cm}$ midline defect in the rectus sheath and a $30 \mathrm{~cm}$ segment of the jejunum and a $6 \mathrm{~cm}$ segment of the transverse colon were gangrenous. The gangrenous bowel segments were resected, and an end-to-end jejuno-jejunal and colocolic anastomosis were done. The patient had an uneventful postoperative recovery.
\end{abstract}

Categories: Emergency Medicine, Gastroenterology, General Surgery

Keywords: epigastric hernia, strangulated, incarcerated, linea alba hernia

\section{Introduction}

A hernia is the protrusion of a viscus or part of a viscus through a defect in its containing cavity wall. The common types of external abdominal hernias are inguinal (75\%), umbilical (15\%), femoral (8.5\%), and incisional (3.5-11\%). Epigastric hernias account for around $1.6-3.6 \%$ of all abdominal hernias and $0.5-5 \%$ of all operated abdominal hernias [1]. A hernia is called strangulated when the blood supply of its contents is compromised. The precipitating cause of strangulation is usually unknown but is presumably some event that forces more abdominal viscera into the sac that can be easily returned. A strangulated epigastric hernia is very rare and is associated with significant morbidity and mortality. We report a rare case of a strangulated epigastric hernia.

\section{Case Presentation}

A 42-year-old gentleman with severe obesity (weight $130 \mathrm{~kg}$, BMI $45.0 \mathrm{~kg} / \mathrm{m}^{2}$ ) presented with epigastric swelling for one year which was initially reducible but became irreducible for one day. It was associated with sudden onset of upper abdomen pain with abdominal distension and non-bilious vomiting for one day.

Review began 03/20/2021 Review ended 03/20/2021 Published 03/22/2021

๑) Copyright 2021

Vemulakonda et al. This is an open access article distributed under the terms of the Creative Commons Attribution License CC-BY 4.0., which permits unrestricted use, distribution, and reproduction in any medium, provided the original author and source are credited.
At presentation, he had tachycardia (pulse rate 110/min) but was maintaining blood pressure. On examination, a 10x15 cm tender irreducible swelling was present in the epigastrium. The skin over the swelling was normal. The rest of the abdomen was soft, but bowel sounds were absent. Ultrasonography (USG) of the abdomen revealed a supra-umbilical midline defect in the anterior abdominal wall. There was herniation of bowel loops and omentum, showing decreased vascularity and absent peristalsis. He was taken up for emergency laparotomy. Intra-operatively, a $7 \mathrm{~cm}$ midline defect was present in the rectus sheath. A hernial sac containing a $30 \mathrm{~cm}$ gangrenous segment of the jejunum $(210 \mathrm{~cm}$ from the duodenojejunal flexure and $160 \mathrm{~cm}$ from the ileocecal junction) and a gangrenous segment of the transverse colon for a length of 6 cm was noted (Figure 1). 


\section{Cureus}
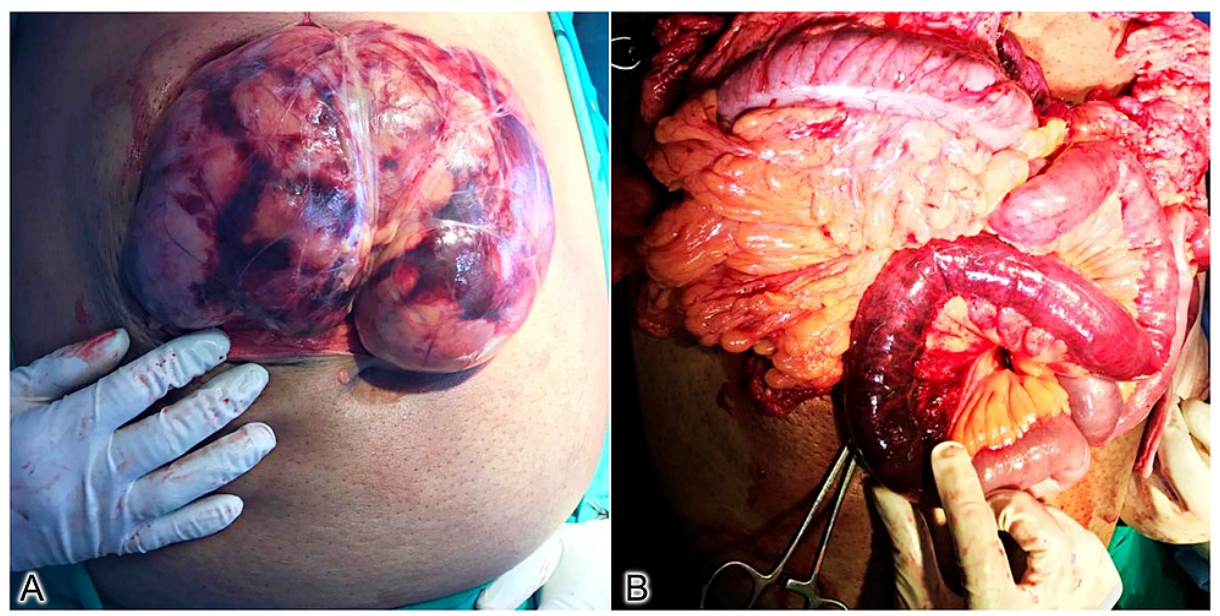

FIGURE 1: Intraoperative photos. (A) Herniated bowel with peritoneal sac. (B) Gangrenous bowel segment.

The gangrenous bowel segment was resected, and an end-to-end jejuno-jejunal and colo-colic anastomosis were done. He had an uneventful postoperative recovery and was discharged on postoperative day 10 .

\section{Discussion}

Any protrusion of tissue through a defect in the linea alba between the xiphoid process and the umbilicus is designated an epigastric hernia [2]. Most of these hernias occur in the immediate three inches above the umbilicus, while those near the xiphoid are exceedingly rare [3]. Epigastric hernias are more common in middle-aged men and obese patients [4]. Risk factors for an epigastric hernia include uncoordinated vigorous synchronous contractions of the diaphragm like coughing, heavy weightlifting, and athletic training.

The oldest theory for epigastric hernia is the perforating vessel theory by Moschowitz. The preperitoneal fat herniates through the defect for the perforator vessels in the rectus, forming an epigastric hernia [5]. This might lead to the protrusion of preperitoneal fat and the intra-abdominal contents through the linea alba. As per his observations, a true epigastric hernia with a peritoneal sac was a rarity, and most cases had only herniation of preperitoneal fat without a sac [6]. Askar proposed a new anatomical basis of the pathogenesis. He suggested a single midline pattern of aponeurotic decussation rather than a triple decussation was responsible for the weakness, leading to herniation [7]. Multiple studies and reports have supported and challenged these observations, but none have been proved convincingly [8,9]. A true epigastric hernia with proper sac and bowel contents is a rare occurrence, and strangulation of bowel contents is even rarer, reported only by a few case reports worldwide $[3,10,11]$.

Epigastric hernias are generally small, containing only preperitoneal fat. Therefore, patients present with periodical sharp localized pain in the epigastric region, often associated with dyspepsia and nausea without any relation to food intake [6]. Clinical diagnosis of a strangulated epigastric hernia is difficult unless there is high suspicion. Gangrene may occur as early as six hours after the onset of strangulation [12]. Patients usually present with a long-term epigastric swelling with sudden onset irreducibility, severe pain, and abdominal distension. Clinically they worsen very quickly. Although it is a clinical diagnosis based on sudden onset irreducibility of a previous reducible swelling, ultrasonography (USG) of the abdominal wall often clinches the diagnosis. USG helps identify the size of the defect, contents of the sac, and their vascularity.

Epigastric hernias, similar to other hernias, need surgery because of their symptomatic nature. Early surgical intervention of an obstructed epigastric hernia is crucial as delay can result in strangulation and the need for bowel resection with prolonged recovery and increased complication rate. If preperitoneal fat or intraperitoneal hernial contents are healthy, they can be reduced and defects in the rectus sheath can be repaired. The repair has to be augmented with mesh placement [13]. However, if the contents are gangrenous, an urgent exploratory laparotomy with resection of gangrenous segment and anastomosis or ileostomy, depending on patients' general condition, is the treatment of choice. Strangulated hernia increases the risks in emergency hernia repair, leading to an increased incidence of surgical site contamination and recurrence [14].

\section{Conclusions}

A true epigastric hernia with a peritoneal sac and bowel contents is a rare occurrence. Therefore, a high index of suspicion for strangulation should be kept in cases of a big epigastric hernia with acute abdominal 
pain and recent-onset irreducibility. Early diagnosis and surgical management are the keys to avoiding bowel resection with prolonged recovery and increased complication rate.

\section{Additional Information \\ Disclosures}

Human subjects: Consent was obtained or waived by all participants in this study. Conflicts of interest: In compliance with the ICMJE uniform disclosure form, all authors declare the following: Payment/services info: All authors have declared that no financial support was received from any organization for the submitted work. Financial relationships: All authors have declared that they have no financial relationships at present or within the previous three years with any organizations that might have an interest in the submitted work. Other relationships: All authors have declared that there are no other relationships or activities that could appear to have influenced the submitted work.

\section{References}

1. Ponten JH, Somers KA, Nienhuijs SW: Pathogenesis of the epigastric hernia . Hernia. 2012, 16:627-633. 10.1007/s10029-012-0964-8

2. Townsend C, Beauchamp RD, Evers BM, Mattox K: Sabiston Textbook of Surgery. Elsevier Health Sciences, 2016.

3. Gatewood: A strangulated epigastric hernia . JAMA. 1916, LXVI:85-86. 10.1001/jama.1916.02580280015007

4. Muschaweck U: Umbilical and epigastric hernia repair . Surg Clin North Am. 2003, 83:1207-1221. 10.1016/s0039-6109(03)00119-1

5. Moschcowitz AV: The pathogenesis and treatment of hernia of the linea alba . Surg Genecol Obstet. 1914, 18:504-507.

6. Moschcowitz AV: Epigastric hernia without palpable swelling. Ann Surg. 1917, 66:300-307. 10.1097/00000658-191709000-00007

7. Askar OM: A new concept of the aetiology and surgical repair of paraumbilical and epigastric hernias . Ann R Coll Surg Engl. 1978, 60:42-48.

8. Lang B, Lau H, Lee F: Epigastric hernia and its etiology . Hernia. 2002, 6:148-150. 10.1007/s10029-002-00740

9. Korenkov M, Beckers A, Koebke J, Lefering R, Tiling T, Troidl H: Biomechanical and morphological types of the linea alba and its possible role in the pathogenesis of midline incisional hernia. Eur J Surg. 2001, 167:909-914. 10.1080/110241501753361596

10. Abu-Zidan FM, Idris K, Khalifa M: Strangulated epigastric hernia in a 90-year-old man: Point-of-Care Ultrasound (POCUS) as a saving kit: case report. Int J Surg Case Rep. 2016, 22:19-22. 10.1016/j.ijscr.2016.03.016

11. Angel JP, Ugalde P, Lopez FP, Fernández JC: Hernia epigástrica con incarceración del antro gástrico [Spanish. Cir Esp. 2015, 93:e9. 10.1016/j.ciresp.2014.09.013

12. Lin MP, Chen YL, Ginger HF: Diagnosis of a gangrenous, strangulated \& incarcerated inguinal hernia by identifying c-shaped small bowel loops and the serrated beak appearance. SAJ Case Rep. 2018, 5:407.

13. Bittner R, Bain K, Bansal VK, et al.: Update of guidelines for laparoscopic treatment of ventral and incisional abdominal wall hernias (International Endohernia Society (IEHS))-Part A. Surg Endosc. 2019, 33:3069-3139. 10.1007/s00464-019-06907-7

14. Dai W, Chen Z, Zuo J, Tan J, Tan M, Yuan Y: Risk factors of postoperative complications after emergency repair of incarcerated groin hernia for adult patients: a retrospective cohort study. Hernia. 2019, 23:267276. 10.1007/s10029-018-1854-5 